\title{
A Web Framework for Advanced and Intensive Nonlinear Time Series Analysis
}

Poster · May 2016

DOI: 10.13140/RG.2.1.2702.2329

CITATIONS

3 authors:

Bruno Bustamante Ferreira Leonor

National Institute for Space Research, Brazil

11 PUBLICATIONS 11 CITATIONS

SEE PROFILE

Reinaldo Rosa

National Institute for Space Research, Brazil

21 PUBLICATIONS $\mathbf{4 0}$ CITATIONS

SEE PROFILE
Walter A. Dos Santos

National Institute for Space Research, Brazil

45 PUBLICATIONS 66 CITATIONS

SEE PROFILE

Some of the authors of this publication are also working on these related projects:

Project $\quad$ Morphological Analysis in Astrophysics and Cosmology View project

UbatubaSat View project 


\title{
A Web Framework for Advanced and Intensive Nonlinear Time Series Analysis
}

\author{
Bruno B. F. Leonor, Walter A. dos Santos, Asiel B. Jr., Reinaldo R. Rosa
}

National Institute for Space Research, S. J. dos Campos, Brazil

brunobfl@gmail.com, walter.abrahao@inpe.br, asiel.bomfin@cptec.inpe.br, rrrosa.inpe@gmail.com

\section{Abstract}

Using the e-Science paradigm, computers play a key role in supporting scientific areas such as those using nonlinear time series analysis to understand seemingly unpredictable behavior. This work presents a web framework supporting researchers in this class of analysis in a cloud environment where they can access, parameterize, initialize and monitor their applications for complex systems analysis. Moreover, new applications, taking into account intensive data analysis from big data files, can be added and managed by researchers on the portal easily. As a case study, techniques such as detrended fluctuation analysis (DFA) and gradient pattern analysis (GPA) will be added and used for intensive time series analysis in the Brazilian Space Weather Program.

\section{Introduction}

The web has been causing a growing impact on scientific research, technological development and society as a whole with its growth over the past few years and has brought a different style of computing mainly into the big data paradigm [1, 2].

This paper presents an e-Science environment named Sentinel to support scientists in their research in a cloud environment using any enabled device to access the web. As a case study, techniques such as detrended fluctuation analysis (DFA) and gradient pattern analysis (GPA) will be added and used for intensive time series analysis in the Brazilian Space Weather Program (EMBRACE) [3] (see Figure 1).

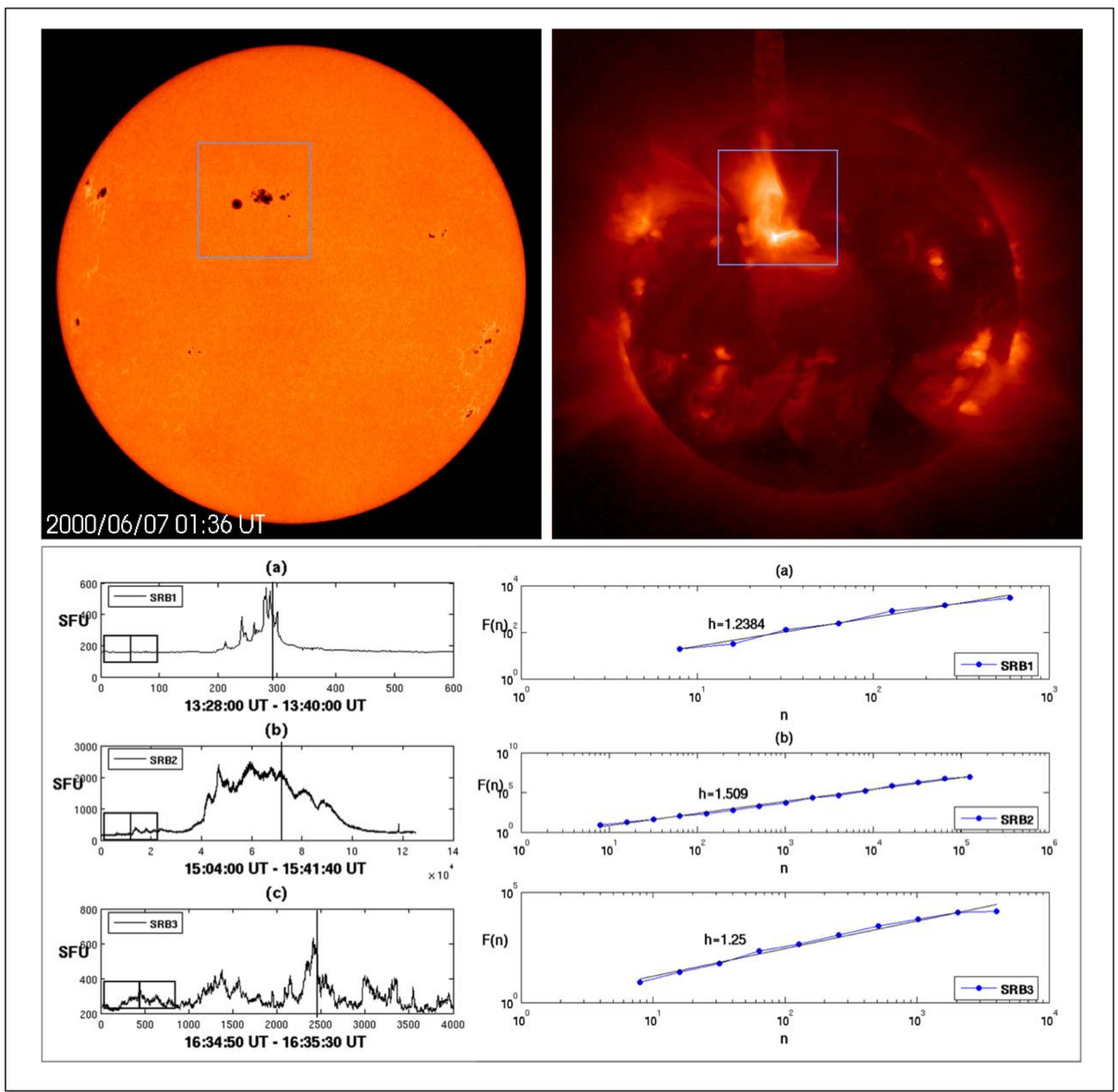

Figure 1: An example of a typical solar flare observed in multiple frequences $(H$-alpha $(H \alpha)$, Soft $X-$ ray and Radio( $3 \mathrm{GHz})$ ) due to a nonlinear plasma process in the solar atmosphere. The evolution of this complex dynamics can be characterized by means of the scaling exponents from DFA analysis.

\section{e-Science}

The term e-Science is commonly used to describe the development of software services infrastructure [4]. This enables access to remote facilities, distributed computing resources, information storage in dedicated databases, dissemination and sharing of data, results and knowledge.

Research in e-Science requires joint efforts and multidisciplinary and can be described by the following characteristics [5]: (1) involves collaboration of researchers computing with researchers from other fields of knowledge, and (2) requires the creation of sophisticated computational methods to handle large volumes of data (Big Data) and/or to perform simulations and programs that require advanced computational solutions for complex systems analysis.

\section{Sentinel}

The environment proposed in this paper is named Sentinel and it is an e-Science environment that aims to provide high performance computing resources to scientists to develop their research. Scientists affiliated to the portal can register their applications and manage them, more specifically, they can access, parameterize, initialize, monitor, analyze and share the results obtained through any device that allows access to the web.

There are two ways to access the portal, as a researcher or guest. The main features for a researcher are shown in Figure 2. Guests can only access the portal to view the results of the experiment and download it when shared by the researcher owner.

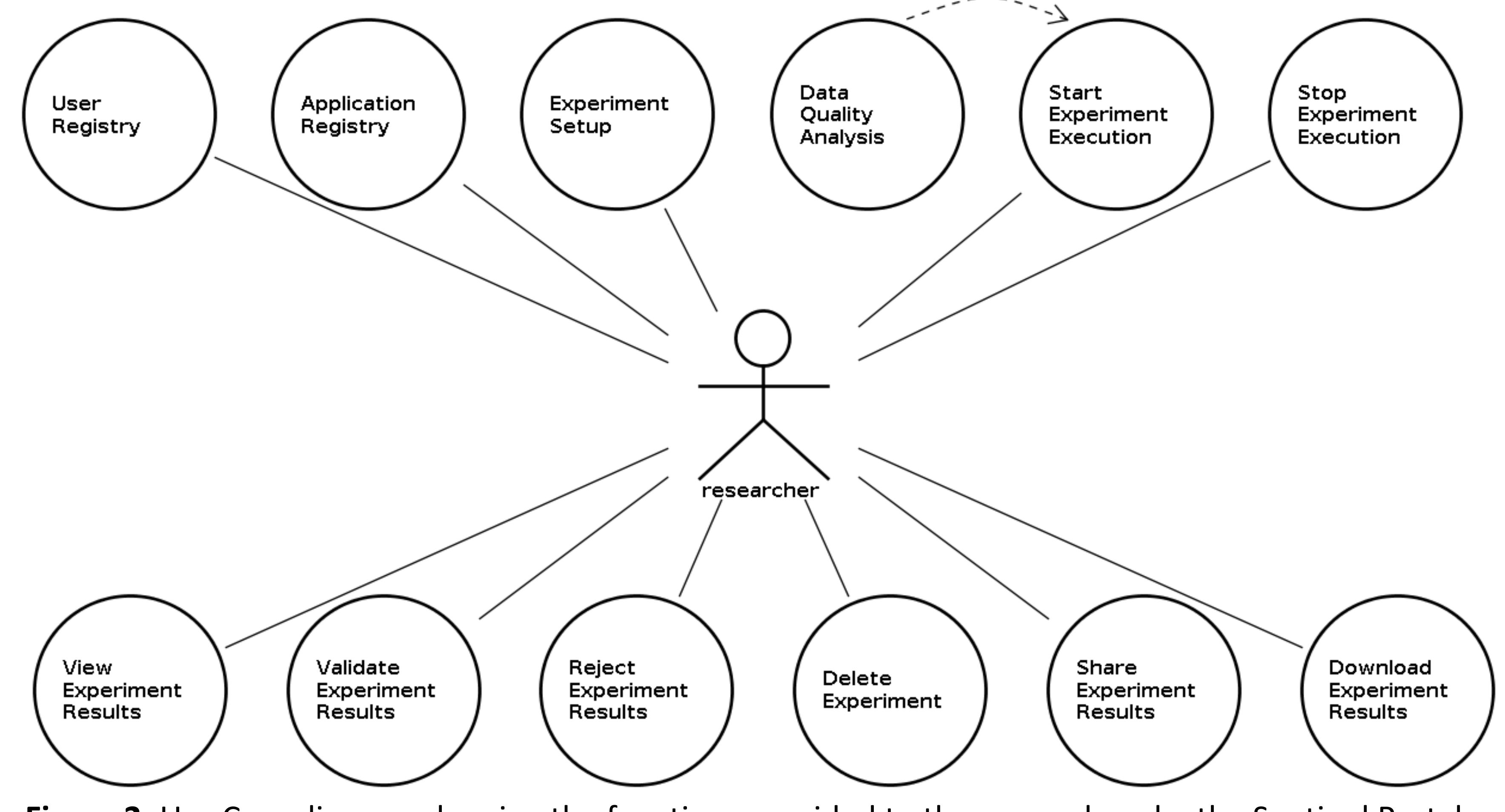

Figure 2: Use Case diagram showing the functions provided to the researchers by the Sentinel Portal.

The researcher has the option to check your input data before starting an experiment through a data quality analysis tool and each application can have its own configuration for analysis.

Through the Dashboard Interface (Figure 3), researchers will have access a set of informations about each experiment, which are: (1) PID - experiment identifier, (2) Application - chosen application, (3) ComputingElement - which node is running, (4) CreationDate - creation date of the experiment, (5) SubmissionDate - request date for execution, (6) StartExectution - initial date of execution, (7) EndExecution - end of the execution date, (8) JobStatus - current situation of the experiment and (9) Actions actions to manage it.

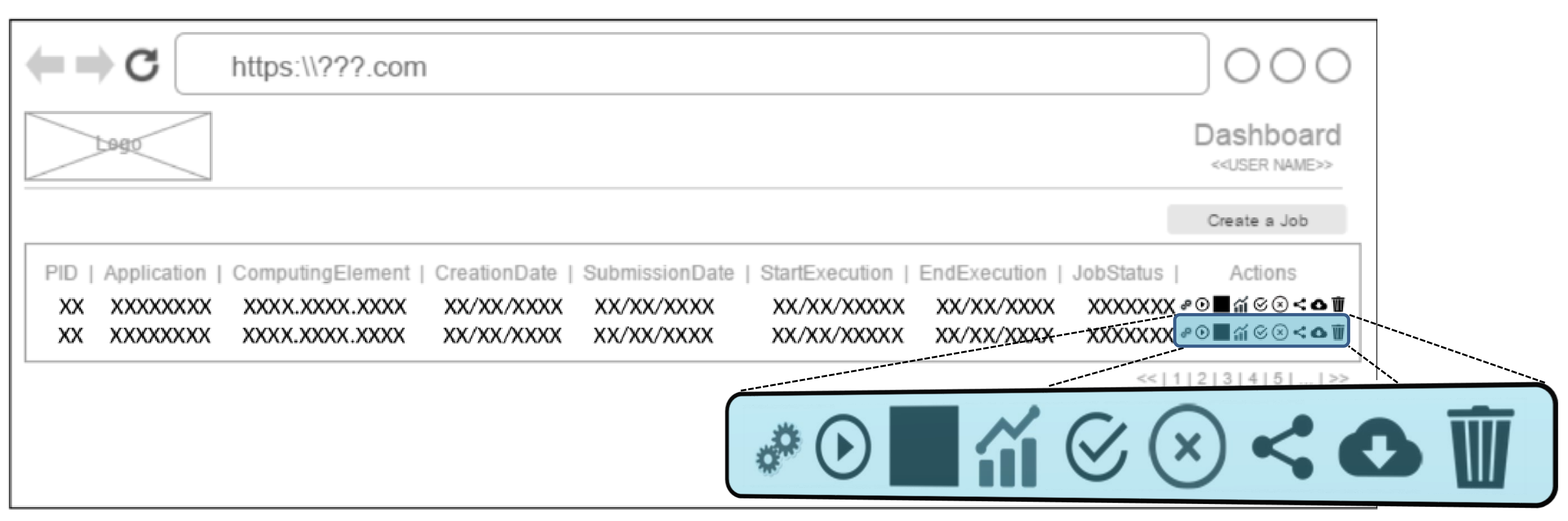

Figure 3: Sentinel's Dashboard interface highlighting the Actions column where the researcher can Setup, Start, Stop, View, Accept, Reject, Share, Download and Delete an experiment and its results. Sentinel portal has too a tool named "Application Registry" that allows the inclusion of new applications, this way new techniques and algorithms may be incorporated into the environment by researchers to complement their studies as well as new visualization tools. To register a new application the researcher should provide some information about it, which enable the portal to create the mechanisms to allow the researcher to manage new experiments.

\section{Case Study}

As a case study, using the Application Registry tool, techniques such as DFA [6] and GPA [7] will be incorporated into the Sentinel portal and used for analysis of time series obtained the Brazilian Space Weather Program, named "EMBRACE".

The EMBRACE program was chosen as a case study for the knowledge and prediction of different phenomena that directly affect human activities, such as solar activity, magnetic storms and ionospheric storms, they have great importance for the well being of society.

\section{Conclusion}

This work introduces a technical conception for an innovative web framework named Sentinel dedicated and suitable for managing e-Science applications.

It is expected that this work will contribute to a more environmentally friendly and safe for e-Science users, where they can gather all the applications used in the development of their research.

The framework prototype has been applied for time series analysis using two techniques, DFA and GPA. Future work will incorporate more challenging experiments and algorithms.

\section{References}

[1] N. Shadbolt, W. Hall, J. A. Hendler, W. H. Dutton,"Web science: a new frontier", The Royal Society, vol. 371, n. 1987, 2013. [2] J. P. Collins, "Sailing on an Ocean of Os and 1s", Science Magazine, vol. 327, n. 5971, 2010.

[3] INPE, "O Programa Embrace", available at: http://www2.inpe.br/climaespacial/portal/oprograma-embrace/, accessed January 2016.

[4] D. Palazzi, L. Silva, L. F. Mendes, W. Gaspar, E. Matos, F. Campos, R. Braga, "Uso de ontologias em projetos de e-science", BDBComp, 2009. [5] Fapesp, "Programa FAPESP de
http://www.fapesp.br/publicacoes/2015/folder_escience.pdf, accessed December 2015. [6] V. V. Morariu, L. Buimaga-larinca, C. Vamos, S. Soltuz, "Detrended Fluctuation Analysis of Autoregressive Processes", Cornell
University Library, 2007 . University Library, 2007.

[7] R. R. Rosa, M. Karlický, T. B. Veronese, N. L. Vijaykumar, H. S. Sawant, A. I. Borgazzi, M. S. Dantas, E. B. M. Barbosa, R. A. 